\title{
Design and Transition of an Emergency E-Learning Pathology Course for Medical Students Evaluation of a Novel Course Concept
}

Christopher Holzmann-Littig ( $\square$ christopher.holzmann-littig@mri.tum.de)

Technical University of Munich, TUM School of Medicine, TUM Medical Education Center

Nana Jedlicska

Technical University of Munich, TUM School of Medicine, TUM Medical Education Center

Marjo Wijnen-Meijer

Technical University of Munich, TUM School of Medicine, TUM Medical Education Center

Friederike Liesche-Starnecker

Technical University of Munich, School of Medicine, Institute of Pathology

Karen Schmidt-Bäse

Technical University of Munich, TUM School of Medicine, TUM Medical Education Center

Katja Weimann

Technical University of Munich, TUM School of Medicine, TUM Medical Education Center

Björn Konukiewitz

Technical University of Munich, School of Medicine, Institute of Pathology

Jürgen Schlegel

Technical University of Munich, School of Medicine, Institute of Pathology

\section{Research Article}

Keywords: Remote Education, Pathology, Flipped Classroom, Medical Education, E-Learning, COVID-19

Posted Date: December 30th, 2021

DOI: https://doi.org/10.21203/rs.3.rs-1188726/v1

License: @) (1) This work is licensed under a Creative Commons Attribution 4.0 International License. Read Full License 


\section{Abstract \\ Background}

Around the world, medical schools emergency-created countless e-learning offerings during the COVID-19 pandemic to provide instruction despite the pandemic. The question now is how to capitalize on this momentum of digitization and how to harness the medical e-learning content created for the future. We have analyzed the transition of a pathology course to show what needs to be considered during such a transition.

\section{Methods}

In the summer semester of 2020, the pathology course at the Technical University of Munich was completely converted to an asynchronous online course. This content was adapted in winter 2021 and incorporated into a flipped classroom concept in which research skills were trained at the same time.

\section{Results}

Screencasts and lecture recordings were the most popular asynchronous teaching formats. Students reported developing a higher interest in pathology and research through group work. The amount of content was very challenging for some students.

\section{Conclusion}

Flipped classroom formats are a viable option when using the pre-existing contents. We recommend checking the contents for technical and didactic quality and optimizing them if necessary. Content on research skills can be combined very well with clinical teaching content.

\section{Background:}

In many medical schools, the COVID 19 pandemic forced the prompt transition to entirely digital teaching (1). Also before the crisis, e-learning had already gained an important role in medical education. The term e-learning basically describes learning in which digital media are used, in the presentation and distribution of learning materials or in communication between learners and/or teachers.(2) In medical education, e-learning includes for instance classic digital media as well as flipped classrooms, communication tools (blogs, chats etc.), electronic assessments, audio and video based tutorials and interactive teaching formats (e.g., digital patient cases educational games etc.) $(3,4)$. However, the development of didactically and content-wise valuable teaching formats is time-consuming and personnel-intensive, which could no longer be realized in this way during the pandemic. Numerous courses based on the principles of Emergency Remote Education have emerged around the world $(1,5)$. Also, the pathology course at the Technical University of Munich Medical School was redesigned under emergency circumstances. Yet, there are significant differences between emergency remote education and long-term planned online courses (5). Emergency remote teaching implies a very short preparation time, combined with limited conception options. Also, changed teaching conditions have to be dealt with, as often no attendance phases can be offered at all due to local restrictions / lockdowns. This can lead to a lower quality compared to courses created under normal conditions (5). At the same time, our course content was to be made usable for the long term. In the development of the course, we planned for this transition from the beginning. In flipped classroom approaches learning materials are provided beforehand so that in the teaching session it can be reflected on the studied content (6). Since flipped classrooms are well suited to improve student learning (3), we aimed at a flipped classroom design that could be used under pandemic and non-pandemic circumstances.

There is an agreement on the importance of physicians' competence to use and conduct research (7). Keeping up with the latest research, being able to critically appraise scientific literature and involve scientific knowledge into clinical decision-making is considered crucial in order to be able to make grounded diagnoses and evidence based therapeutic decisions (8). Also, the Canadian Medical Education Directives for Specialists (CanMEDS) emphasizes the importance of research by defining it as one of the core competencies (9). The importance of research is also underlined in the German Master Plan for Medical Studies 2020 (10). Nevertheless, recent studies have shown that only a minority of medical students is inclined to research or even a research career $(11,12)$. As a result, diverse research-related courses are emerging in curricular and extra-curricular research programs within many medical schools (13-21). To meet the demand for research skills, we integrated the training of research skills in the pathology course. Furthermore, according to Kaufmann and Mann, "Learning is enhanced when it is relevant, particularly to the solution and understanding of real - life problems and practice."(22). Thus, we aimed to encourage medical students' interest in research as well as to increase their knowledge on research by engaging them in small research projects $(7,11,23)$. The SelfDetermination Theory (SDT) built the theoretical framework when designing the course. SDT presents a theory of human motivation that assumes humans innate tendency to grow and outlines three core psychological needs that foster the intrinsic motivation: Autonomy, Competence and Relatedness. Autonomy refers to the humans' needs to feel in control of their own behaviors and goals. Competence indicates humans' feeling to have skills and be able to success. Relatedness refers to the need to experience a sense of belonging (24). While designing the online pathology course, we aimed to meet the students' needs and strengthen their feelings of autonomy, competence and relatedness in order to enhance their intrinsic motivation and interest in research. Thus, in addition to achieving knowledge in pathology, students in this course were to gain the skills necessary to work independently in a scientific manner (competence). Their autonomy was to be promoted early on through the flipped classroom approach, and relatedness was to be fostered through working in small groups.

Self-directed learning, an "increasingly essential [method] in the development and maintenance of professional competence" implies on the one hand "acceptance of personal responsibility for learning" and "personal autonomy" and is regarded as a "method of organizing learning and instruction with the tasks of learning primarily in the learner's control" (25). This model was to be addressed through largely autonomous, yet professionally guided learning. 
The purpose of this work was to investigate the students' satisfaction with the new course concept compared to the traditional teaching methods as well as the Emergency Remote Education course. In addition, the students' attitude towards the pathology and research after attending the new course should be evaluated.. Furthermore, it should be investigated if the students lack direct contact with the lecturers in the new course concept. At the same time, we would like to describe the transformation of an originally classical pathology course via an Emergency Remote Education course to a new course model and thus, give suggestions on how to create new course concepts with Emergency Remote Education contents and which pitfalls should be considered.

\section{Methods:}

\section{Course development}

The original Pathology class took place during the first clinical year of medical school, was mandatory, and was completed with a graded examination. The class consisted of lectures and group seminars and had been held face-to-face. It covered the topics of general pathology and neuropathology (all other special pathology topics are included in an integrated lecture in the second clinical year of medical school).

The new General Pathology Online class was established in two development phases.

\section{Emergency Remote Education (5) Concept (“DigiPath"), Summer Semester 2020}

With 31 teaching units, the course covered all previously taught aspects of general and special pathology (Supplemental table 1). The content was presented in an asynchronous (i.e., it could be completed at any time of the day) e-learning module ("DigiPath"). Screencasts (i.e., videos showing a presentation discussed by a speaker), animated videos, or lecture recordings were used. In six units, only lecture slides were presented. This entirely asynchronous approach was necessary as during the first phase of the pandemic many students were employed as auxiliary staff in the clinic and therefore had to be able to attend classes more flexibly. Knowledge tests including single or multiple-choice questions, drag-and-drop tasks open questions and matching questions were built in between the learning sections. Only after answering the tests correctly, the students were able to move on to the next unit. There was no limit to the number of attempts. The week's units were sequentially activated at the beginning of each week and available until the end of the semester. As selfdirected learning should include the opportunity to ask questions (22), the students were offered voluntary virtual meetings with the lecturer at the end of each week. Due to the pandemic, final oral examination had to be cancelled.

\section{Flipped Classroom Concept, Winter Semester 2020/2021}

In the next step, a flipped classroom concept was developed, consisting of the asynchronous e-learning ("DigiPath") module followed by seminar module (project phase, "Projects in Pathology") (22), in which knowledge on specific pathology topics was to be deepened and research skills (scientific thinking, management of scientific projects and teamwork) were the course was developed by the pathology lecturers, and there was accompanying consultation on didactics by the TUM Medical Education Center. We used Moodle ${ }^{\circledR}$ as the learning management system. Kern et al. have proposed a six-step process of curriculum development (26) that we used in the development process. These steps are: the identification of the problem, a (targeted) needs assessment, a definition of goals and objectives, the selection of educational strategies, the implementation and the evaluation process (26). Figure 1.

\section{Flipped Classroom concept, part 1: asynchronous elearning module "DigiPath"}

The asynchronous contents were slightly modified, and the remaining 30 units were divided into five subjects: general pathology, inflammation/immunology, general tumorology, special tumorology and neuropathology. The contents were presented exclusively in screencasts and animated videos. Due to technical problems in the learning management system, the examination tasks between the units had to be suspended. The course units were activated sequentially on a daily basis to allow completion by the start of the seminar phase and were available until the end of the semester. A weekly "meet the expert session" was provided in which cases fitting to the actual topics were discussed and questions were answered.

\section{Flipped Classroom Concept, part 2: project phase ("Projects in Pathology")}

After the planning of the course design, a training for medical teachers was developed. The teachers should act as coaches who support the students in their learning process and support the development of the students' research skills. They received a training on the new course materials and on how to conduct group sessions developing a project. These trainings were organized together with and guided by TUM Center of Key Competencies, materials on teaching research skills were produced by TUM Medical Education Center.

Ommering et al. (2020) suggested dividing students into small groups and assigning lecturers with research expertise to each group when designing a course with the focus on training research skills (7). Consequently, 20 groups with a maximum of 8 students each were built. In selecting research teaching content, we followed the graduate attributes of Laidlaw et al. (27), although not all of these could be implemented in one single course. First, each group was assigned one pathology subject that had to be studied in depth. Each topic had been studied in the DigiPath module before. On the basis of this topic, the way from general pathology and pathophysiology background to a clinical diagnosis and therapy was developed using a problem-based (28) approach. In the end, a scientific poster on this topic was to be created. Furthermore, the skills "management of scientific projects", "teamwork", and "scientific thinking" - (literature research, critical reading, and designing scientific posters) were trained. Following the AMEE guide on developing research skills in medical students (29), we used a blended learning concept, with case based learning (using patient centered cases) and developed a course curriculum integrating research skills and clinical knowledge (29). Screencasts for preparation at home were developed. Considering the implications that Kaufman and Mann (22) derived from social cognitive theory (30), we created a goal that students had to achieve at the end of the course, thus supporting the learning process. Considering the suggestions of Ommering et al. and in terms of Self-Determination Theory (SDT), we gave the students freedom to organize themselves within the group and 
conduct their research project individually in order to foster their feelings of autonomy, and thus enhance their feelings of the ownership of their research, which is seen important to persist one activity successfully (7).

Due to a worsening of the pandemic, the project phase had to be held in virtual classrooms. As presenting and discussing new knowledge promotes deep learning and offers opportunity to train the ability to critically appraise the scientific work of others (7), a symposium was planned. Because this symposium could not take place, yet the final posters were discussed within the groups. Each group discussed and evaluated three posters from the other groups on the basis of the prepared criteria for the quality of a scientific poster. (Table 1).

Table 1: Transformation of the original class

\begin{tabular}{|c|c|c|c|}
\hline Original Pathology Class & Emergency Remote Education (5) Concept & Flipped Classroom Concept & \\
\hline \multirow[t]{2}{*}{$\begin{array}{l}\text { Lectures \& } \\
\text { Seminars }\end{array}$} & \multirow[t]{2}{*}{$\begin{array}{l}\text { E-Learning module } \\
\text { "DigiPath" }\end{array}$} & $\begin{array}{l}\text { E-Learning module } \\
\text { "DigiPath" }\end{array}$ & $\begin{array}{l}\text { - } 30 \text { asynchronous lessons } \\
\text { - } 38 \text { screencasts } \\
\text { - Meet the Expert } \\
\text { - No Quizzes }\end{array}$ \\
\hline & & $\begin{array}{l}\text { Project phase "Projects } \\
\text { in Pathology" }\end{array}$ & $\begin{array}{l}\text { - } \text { small group teaching } \\
\text { - } 20 \text { Groups with } 9 \text { participants each (1 } \\
\text { - in-depth study of one topic } \\
\text { - } \text { Training of core competencies: } \\
\text { - scientific thinking } \\
\text { - management of scientific projects } \\
\text { - } \text { teamwork } \\
\text { - Poster presentation }\end{array}$ \\
\hline
\end{tabular}

\section{Evaluation}

The study was approved by the Ethics Committee of the Medical Faculty of the Technical University of Munich under the code $340 / 20$ S-KH. All participants gave a written informed consent statement before answering the questionnaires. The surveys were performed using EvaSys (https://evasys.de/).

The pathology course was assessed by the students as part of the general semester evaluation (short evaluation) . In addition, students were asked to complete a larger survey for deeper understanding. In this survey, each individual course section was rated with school marks (ranging from 1 = very well to 6 $=$ unsatisfactory) as this system is generally used in the evaluations of classes in our university (satisfaction with the course units). All further scale based questions were designed with five point Likert scales as these are the most commonly use type of Likert scales (31) Questions on the usability and structure were designed based on prior survey items by Liu, Lewis and Herrmann (32-34). In summer semester 2020 both surveys were sent to 185 course participants, in winter semester 2020/2021, to 157 participants. The surveys took place directly after the end of each semester, i.e., in July 2020 and February 2021 . All surveys were closed after 10 days. All students were invited via e-mail. No reminders were sent out as not to reduce respondence in other evaluations and surveys at the end of each semester. Participation in the surveys was voluntary. The survey questions and results can be seen in Supplemental Tables 2 and 3.

\section{Statistics:}

Statistical analysis was performed using JASP, Version 0.14.1.(35). For descriptive analyses, mean values with standard deviation and percentages were built, presented as mean [SD]. The overall satisfaction with the course units was correlated to the different types of teaching formats (e.g., screencasts, lecture recordings etc.) using point biserial correlation analysis with Pearson's r (36) A p-value of 0.05 was considered statistically significant. Free text comments were evaluated and categorized by two different team members. Anchor examples were chosen separately and taken for each section after discussing them. Since the course structure differs between summer and winter semesters as described above, and there was less time available to complete the "DigiPath" course in the winter semester, the results for the asynchronous course sections in the summer and winter semesters are presented separately.

\section{Results:}

\section{Participants}

A total of 29 students (emergency remote (5) phase, summer semester 2020) and 68 students (transition phase, winter semester 20/21) filled in the short evaluation as part of the general semester evaluation. A total of 23 students filled in the large questionnaire in the emergency phase, 27 did so in the second phase. $92 \%$ of the students were younger than 25 years. $74 \%$ were female $-66 \%$ of all invited students were female.

\section{Overall satisfaction}

In the long survey, the asynchronous teaching units in the emergency remote education (5) phase were rated with an average grade of 1.51 , followed by a 1.98 in the flipped classroom concept. The project phase was rated better with 1.44. (Since this is the usual practice in our faculty, German school grades were used 
to evaluate satisfaction, 1 being the best, 6 being the worst.) However, in the short survey as part of the general semester evaluation, a decrease from 1.56 to 2.32 was observed in the overall satisfaction (Table 2). The individual grades of the course days are listed in Supplemental Table 1.

Table 2: Mean grades of courses

\begin{tabular}{llll} 
Item & $\begin{array}{l}\text { Original Course } \\
\text { (students were obliged to } \\
\text { evaluate directly after each } \\
\text { unit) }\end{array}$ & $\begin{array}{l}\text { Emergency Remote (5) Concept } \\
\text { (Asynchronous E-Learning module only, }\end{array}$ & Flipped Classroom Concept \\
\hline $\begin{array}{l}\text { Overall grade (part of } \\
\text { general semester } \\
\text { evaluation) }\end{array}$ & & 1.56 & 2.32 \\
\hline $\begin{array}{l}\text { Average grade of course } \\
\text { units (long survey) }\end{array}$ & 1.94 & 1.51 & 1.71 \\
& & & $\begin{array}{c}\text { Asynchronous E- } \\
\text { Learning module } \\
\text { ("DigiPath”) }\end{array}$ \\
\hline
\end{tabular}

\section{Asynchronous E-Learning Module}

\section{Satisfaction with different teaching materials}

In the emergency remote (5) phase, in the evaluation of the course units screencasts / animated videos $(r=-0.515, p<0.001)$, case vignettes $(r=-0.482$, $p<0.001)$ and scripts $(r=-0.354, p=0.005)$ were inversely correlated to higher (worse) school grades for the each unit. Lecture recordings were correlated to higher (worse) school grades $(r=0.252, p=0.048)$ for each unit. According to the free text comments, video recordings still improved learning success due to the additional explanations by lecturers. Units in which only lecture slides were offered received the worst ratings. Accordingly, in the free text comments, students stated that they understood significantly less when only lecture slides were offered.

"Even though I wouldn't say that I didn't understand [the topics], I took significantly less with me when only slides were uploaded".

Asking students which teaching formats they considered suitable, screencasts (summer 4.55 [0.74], winter 4.22 [1.09] / five points on a Likert scale ( $1=$ worst, 5 = best)) and animated videos (summer 4.63 [0.60], winter 4.63 [0.84]) were favored. Lecture recordings were regarded less suitable (summer 3.79 [1.82], winter 4.13 [1.23]).

Regarding preferred teaching units, neuropathology units were mentioned in $86 \%$ (summer) and $79 \%$ (winter). In the free text comments, short and informative screencasts, and animated videos with focus on essential contents, short handouts and clear learning objectives were cited. Shorter videos were regarded as more exciting and easier to memorize. Accordingly, students suggested to offer all the material as short screencasts.

"Some lecturers presented their material in a screencast much more concise and shorter than it would probably have been in a lecture. That was good because it allowed the essentials to stick better and it was more exciting to listen to".

In the free text comments, students appreciated the asynchronous learning format. $22 \%$ of students in summer (5 out of 23 ) and $15 \%$ of students in winter semester (4 out of 27) addressed the ability to replay and to pause videos to topics that were not well understood as very beneficial. Furthermore, flexible access time was appreciated.

"Overall, everything was really very clear and extremely well done. And because you could watch the videos when you are awake and fit (and take breaks when your concentration drops), you absorb a lot more than usual. On the contrary, I had the feeling that I had just really understood many topics."

While the weekly provision of the course units in the emergency remote (5) concept was perceived positively (for not being overwhelmed by materials), the daily release of the lecture units in the flipped classroom concept was criticized as the amount of material added up quickly leading to perceived time pressure. Furthermore, students criticized learning units with high information density. One student reported the "feeling of being overwhelmed". In this regard, students expressed their wish for more selection and clear focus on the essential content.

\section{Usability and structure}

Most respondents agreed that the course was easy to use (summer 4.77 [0.69], winter 4.38 [0.88] / 5 points, $1=$ worst, $5=$ best). However, in the emergency remote (5) concept, several students reported having difficulties loading and playing the videos leading to increased processing time of the course. In some course units, poor picture and sound quality were also mentioned as disturbing factors. Also, most respondents agreed with the statement that the course structure is clear (summer 4.64 [0.90], winter 4.52 [0.73] / 5 points). $17 \%$ of students in summer ( 4 out of 23 ) and $15 \%$ of students in winter semester (4 out of 27 ) indicated a need for an additional scriptum providing more learning structure. 
Clarity of the information provided was rated higher in the emergency remote (5) phase than in the flipped classroom concept (4.24 [1.04] vs 3.60 [0.91] / 5 points). Students did not agree to have had problems answering the quiz after the course units in the emergency remote (5) phase (1.74 [0.99] / 5 points). In the free text comments, the quizzes offered in the emergency remote (5) concept were perceived as enriching. According to the students, quizzes give the opportunity to test the learning success and give reward for learning and focusing on the videos.

"I often had the feeling that I concentrate much more on the videos, because everything could potentially come up in a question. And because it's a great feeling when you can answer the questions correctly right away!"

While $86 \%$ of the students rated the amount of time as appropriate in the emergency remote (5) phase, this was the case in only $44 \%$ in the flipped classroom phase. $77 \%$ and $22 \%$ rated the amount of material as adequate in the emergency remote (5) phase and the flipped classroom phase, respectively.

\section{Missing of face-to-face interaction}

The statement "Direct interaction with lecturers in class was missing for better understanding" was answered heterogeneously (summer: 2.81 [1.44], winter: 3.04 [1.04] / 5 points). Accordingly in the free text comments, face-to-face teaching was not missed by the majority of the students.

$13 \%$ of students in summer ( 3 out of 23 ) and $7 \%$ of students in winter semester ( 2 out of 27 ) missed a final examination. According to the students, the absence of the exam significantly restrains learning success. Consequently, they expressed their wish for an exam to ensure learning.

"I find the system without a final exam questionable. You only really prepare for the topics if you are asked about them in some way".

\section{Perceived understanding}

Agreement with the statement "I have understood the course contents" was found in the majority of the students, with a decrease in winter semester (3.95 [1.24] vs $3.16[1.11])$.

\section{Project phase (,Projects in Pathology“):}

The majority of students considered the group size to be appropriate, averaging $4.81(0.49)$ / 5 points, and the working atmosphere as pleasant with 4.74 (0.71) / 5 points.

Also in the project phase, absence of face-to-face interaction was not considered to be hindering cooperation (2.67 [1.33] / 5 points), communication (2.63 [1.39] / 5 points) or learning gain (2.63 [1.47] / 5 points). However, classroom teaching was demanded by some students in the free text comments.

Furthermore, students were very satisfied with the support provided by the lecturers (4.89 [0.32] / 5 points). 100\% of the students agreed with the maximum number of 5 points that the lecturers were available for questions, responded to suggestions and formulated criticism fairly and constructively.

The knowledge gain on research skills was rated with an average of 4.15 [0.91] points. In particular, knowledge gain was perceived highest in poster development (4.41 [0.57]) and the critical examination of scientific content (4.37 [0.74] points), followed by scientific research (4.26 [0.81]) and management of scientific projects (3.82 [1.00]). The knowledge gain in terms of teamwork was rated slightly lower at $3.52(0.94)$.

The students felt their interest in pathology had increased by the group work (4.04 [1.04] / 5 points). Likewise, they rather agreed to have an increased interest in scientific work (3.93 [1.14]/5 points).

The responses to the open question of what students liked best in the project phase revealed that students particularly appreciated the interactivity. The opportunity to work together with fellow students on a project, to deal with a topic intensively and to design a poster were perceived very pleasant and instructive. $30 \%$ of students ( 8 out of 27) mentiones the focus on the research (including guidance on the use of medical search engines, practicing critical reading and designing a poster) which, according to the students, is often neglected in medical studies, was perceived as helpful.

"I found it very helpful to have a fixed course that encourages and accompanies research so that you are not completely on your own and lost."

Motivation and support provided by the lecturers who "encouraged students to remain curious" was also highlighted by the students. The students found the schedule of the project phase to be reasonable. One student assessed the workload as appropriate, another student found it to be inappropriately high.

As negative comments, 4 students (15\%) expressed their wish for clearer communication, criticizing goals and schedule were not clear and the deadline for submitting the poster was communicated incorrectly. One student explained that the pandemic made it difficult to organize at times and expressed the wish for more structure.

The dismission of the poster presentation was also perceived negatively. Two students expressed their doubts to what extent the mutual evaluation of the posters from other groups can contribute to the learning success. One students fount the opportunity to evaluate posters of the other groups generally good but described finding the evaluation difficult due to the specific character of the topics. Furthermore, the students found it difficult to discuss and evaluate the posters of the other groups, as many topics were quite specific. Therefore, students proposed to broaden the topics and assign the same topic to several groups for elaboration.

\section{Discussion:}


Emergency remote education needs to be set up quickly leading to several disadvantages in course design and quality (5). However, quite likely, the COVID-19 crisis might lead to an acceleration of the digitalization in medical education (37).

We analyzed the transition of an emergency remote education (5) pathology course to a novel flipped classroom approach including a general pathology / neuropathology e-learning module with meet the expert sessions, followed by a project phase integrating intensified pathology studying using an problembased learning approach (28) and research skills training that can switch between pandemic and non-pandemic mode at any time, as the project phase can also be held virtually. We could observe that the general satisfaction with the course has increased in the further development compared to the Original Course concept. However, the Emergency Remote (5) phase was rated better than Flipped Classroom phase, in both, in the long and in the short survey. With regard to teaching materials, screencasts and animated videos were identified as the most suitable teaching formats. The neuropathology course units with short and informative screencasts with focus on essential contents, short handouts and clear learning objectives were identified as the most preferred units. In general, the students appreciated the asynchronous learning format. Especially, the flexibility in access and operation were appreciated. The usability of the course was rated positive and the course structure was perceived as clear. The clarity of the information provided and appropriateness of amount of time and material were rated higher in the emergency remote (5) phase than in the flipped classroom phase. Face-to-face interaction with the lecturer was not missed by the majority of the students. The perceived understanding of the course units decreased from the Emergency Remote (5) phase to Flipped Classroom phase. The project phase was perceived very positively by our participants. Students appreciated the opportunity to work together with fellow students on a project. The knowledge gain on research skills was rated high.

\section{Transition of asynchronous contents}

In line with the literature, our results reflect the benefits of asynchronous teaching, (e.g. being able to study at ones one pace, not depending on time and place) (38). This flexibility was most important during the pandemic as several medical students helped as volunteers in hospitals but might be beneficial in the future as well possibly supporting self-directed learning (22).

In line with the literature (39), we demonstrated that screencasts (that can be produced in high quality with relatively little effort) are an appealing format for elearning, especially when combined with other didactic methods. However, elaborated screencasts / videos with animations and drawings were especially considered to be arousing interest. Using simple lecture recordings may be helpful for students not able to attend a synchronous lecture or to repeat the contents. We therefore recommend providing screencasts and lecture recordings wherever possible.

However, the duration of the videos needs to be reflected as length and therefore concentration is a limiting factor in e-learning (40). Furthermore, density of information seems to determine the success of the learning. We therefore recommend paying attention to the length and information density of videos and screencasts and offer short videos and screencasts with focus on essential contents.

Moreover, a logical structure and clearly defined objectives (which are always of particular importance in the development of a teaching unit (41) could be identified as factors that contribute to perceived learning success.

The quizzes between the units were appreciated and perceived as enriching as they were seen as opportunity to test the learning success and motivation to focus on the videos. Having solved the technical issues, the quizzes will be implemented in the upcoming semester again. In line with this, a final exam was missed by several students, most likely reflecting the fact that "assessment drives learning" (42). New course concepts may also lead to the need of new examination concepts - this should be considered early when designing new course concepts out of the emergency remote education (5) teaching contents.

Also, sound and picture quality seem to affect the perception of the course and possibly also the students' motivation. At least in our faculty in the emergency phase it was sometimes regarded challenging to provide videos at high picture and sound quality.

Therefore, we recommend, in addition to didactic competencies, to promote the competence of teachers in the use of media and online services in teaching by providing them with appropriate training and assistance in the use of digital technologies. It might be advisable to set up a working group supporting medical teachers in creating e-learning contents. At TUM Medical Education Center, we have therefore built an e-learning team including several student assistants supporting medical teachers in creating the best possible online contents using up-to-date techniques. This might not have been possible in the Emergency Remote Education (5) Phase but this will surely be needed on the way to professionalization of the rapidly produced contents.

However, tightening the schedule by shortening the asynchronous e-learning module to make them usable in a flipped classroom concept left some students overloaded. In winter semester, students were less satisfied with this module and were significantly less likely to consider the module size appropriate. The decrease in satisfaction can be explained by the elimination of the quizzes in the Flipped Classroom phase, which were particularly appreciated by the students. Furthermore, the daily activation of the course units, which was perceived as overwhelming by the students, could have led to a decrease in satisfaction. This highlights a problem with transitioning emergency remote (5) education contents into new teaching formats. Therefore, we recommend to pay particular attention to the scope of content and time when converting the emergency remote (5) course contents in the Flipped Classroom course contents.

\section{Transition to seminars}

The project phase was designed in a new manner, combining intensified studying of one pathology topic per group (using a problem-based learning (28) approach) on the one hand and teaching research skills on the other. In line with the theory, the students appreciated the interactivity and the opportunity to work together with fellow students on a project during the project phase („Projects in Pathology“). Ommering et al. (7) refer to Bandura's concept of selfefficacy, defined as individuals' belief in one's own ability to accomplish a task, assuming that individuals are likely to engage in activities if they believe that they can succeed these activities (43). Ommering et al. assume that if students are more confident in their research abilities, the chances of continued

Page $7 / 11$ 
engagement in research increase (7). In line with Ommering et al. our students stated that their interest in pathology had increased by the group work along with their interest in scientific work.

Working in small groups, facilitates exchange between peers and with the lecturer and allows closer mentoring. Thus, working in small groups increases the chances that students will gain more confidence about their research skills and fosters their positive self-efficacy beliefs (7). When building new flipped classroom concepts out of the emergency remote education (5) materials, we recommend to keep group size small and limit in to 8 people.

The project phase („Projects in Pathology“) was found suitable to practice research skills that in the opinion of our respondents are often lacking. This is in accordance with the current literature as Vereijken et al. already showed in their survey under medical students that research practices promote the students' research motivation enhancing the idea that research is relevant to learning. They suggested to include elements of professional practices that stimulate students' enthusiasm for research and focus students' attention on the way research findings are produced (23). Furthermore, in the theory of connectivism (44), which is commonly used for online education, being able to see connections between fields, ideas, and concepts is regarded a core skill (45). However, students need to be trained in recognizing these connections to optimally studying new contents. Therefore, our goal was to link pathology content and research skills with case-based learning using a flipped classroom concept with seminars.

Surely, it will not be possible or appropriate to weave research skills training into every course. However, linking a clinical subject to this knowledge content may be more likely to engage students with research topics than if they are not integrated but taught separately in their own courses. In our medical school we therefore want to expand this concept based on these results in further courses.

Furthermore, when creating flipped classroom concepts and especially when connecting teaching of classical contents combined with research skills contents, the teaching staff should be trained beforehand in order to reach effective lessons .

\section{Strengths and limitations}

Our study describes the transformation from a classical pathology course to a modern pathology course with a flipped-classroom approach which can switch between a fully digital and a face-to-face mode at any time and gives practical and differentiated insights in the course development process. In addition, the present study shows the possibilities and gives practical advices on how clinical teaching can be linked to teaching about research skills.

However, there are weaknesses that need to be addressed. The response rate of the students was quite low, probably due the fact that all evaluations were done simultaneously at the end of the semester and the length of this evaluation. Furthermore, we cannot provide examination results as oral examinations had been suspended and students will only wright the pathology exam after another integrated lecture in the following study year. Therefore, the impact on the knowledge cannot be proven.

\section{Conclusion}

Transformation of emergency education (5) materials needs to be carried out carefully having in mind didactic methods, technical and organizational issues. Technical and didactic quality of the emergency contents need to be revised and the amount of teaching materials provided should be analyzed. Flipped classroom contents can be used to combine classical clinical teaching with teaching of research skills to improve students' interest in research. Our course concept might help to build new courses using the rapidly developed emergency remote education (5) materials and avoid wasting them. Thus, such materials might be used to generate new, creative, and didactically high-quality course concepts, so that despite all the hardships during the pandemic, there may also be new opportunities and chances for medical teaching.

\section{Declarations}

\section{Ethics approval and consent to participate}

The study was approved by the Ethics Committee of the Medical Faculty of the Technical University of Munich under the code $340 / 20$ S-KH. All participants gave a written informed consent statement before answering the questionnaires. All methods were performed in accordance with the relevant guidelines and regulations. The study adheres to the Declaration of Helsinki.

\section{Consent for publication}

Not applicable.

\section{Availability of data and materials}

All relevant data can be found in the supplement in aggregated form, the publication of the original datasets is not possible due to German and faculty data protection requirements.

\section{Competing interests}

The authors declare that there is no conflict of interest.

\section{Funding}

There was no funding for this study. 


\section{Authors' contributions}

$\mathrm{CHL}$ designed the questionnaires, designed materials for the teaching of research skills, analyzed the results and wrote the manuscript, $\mathrm{NJ}$ designed the questionnaires and wrote the manuscript, MWM gave substantial input to the course development and revised the manuscript critically, FLS was involved in the course design, the design of the study methods and revised the manuscript critically, KSB designed materials for the teaching of research skills and revised the manuscript critically, KW designed the questionnaires and wrote the manuscript, BK designed the new course concept and revised the manuscript critically, JS designed the new course concept, developed several new course contents, supervised the study and revised the manuscript critically.

\section{Acknowledgements}

We thank our colleagues at the Center for Key Competencies for their support of this course. We thank all lecturers for designing new course materials.

\section{References}

1. Mian A, Khan S. Medical education during pandemics: a UK perspective. BMC Medicine. 2020;18(1):100.

2. Mediendidaktik [Internet]. Beltz Juventa. 2012. Available from:

https://www.beltz.de/fachmedien/erziehungs_und_sozialwissenschaften/enzyklopaedie_erziehungswissenschaft_online_eeo.htmltx_beltz_educationency educationencyclopedia\%5Baction\%5D=article\&tx_beltz_educationencyclopedia\%5Bcontroller\%5D=EducationEncyclopedia\&cHash=f4735a442d71 f4212b;

3. Hew KF, Lo CK. Flipped classroom improves student learning in health professions education: a meta-analysis. BMC Med Educ. 2018;18(1):38.

4. Kuhn S, Frankenhauser S, Tolks D. [Digital learning and teaching in medical education: Already there or still at the beginning?]. Bundesgesundheitsblatt Gesundheitsforschung Gesundheitsschutz. 2018;61(2):201-9.

5. Hodges C, Moore S, Lockee B, Trust T, Bond A. The Difference Between Emergency Remote Teaching and Online Learning. Educause Review. 2020.

6. Eaton M. The flipped classroom. Clin Teach. 2017;14(4):301-2.

7. Ommering BWC, van Diepen M, van Blankenstein FM, de Jong PGM, Dekker FW. Twelve tips to offer a short authentic and experiential individual research opportunity to a large group of undergraduate students. Med Teach. 2020;42(10):1128-33.

8. Ommering BWC, van Blankenstein FM, Waaijer CJF, Dekker FW. Future physician-scientists: could we catch them young? Factors influencing intrinsic and extrinsic motivation for research among first-year medical students. Perspect Med Educ. 2018;7(4):248-55.

9. Frank JR, Snell L, Sherbino J, Boucher A. CanMEDS 2015. Physician Competency Framework Series I. 2015.

10. Bundesministerium fuer Bildung und Forschung. Masterplan Medizinstudium 2020 Berlin, Germany [Available from: https://www.bmbf.de/de/masterplan-medizinstudium-2020-4024.html.

11. Ha TC, Ng S, Chen C, Yong SK, Koh GCH, Tan SB, et al. Inclination towards research and the pursuit of a research career among medical students: an international cohort study. BMC Med Educ. 2018;18(1):86.

12. Tan S-B, Koh GC, Ding Y-W, Malhotra R, Ha TC, Pietrobon R, et al. Inclination towards a research career among first year medical students: an international study. South East Asian J Med Educ. 2011;5:49-59.

13. Ommering BW, van Blankenstein FM, Wijnen-Meijer M, van Diepen M, Dekker FW. Fostering the physician-scientist workforce: a prospective cohort study to investigate the effect of undergraduate medical students' motivation for research on actual research involvement. BMJ Open. $2019 ; 9(7): e 028034$.

14. Harding CV, Akabas MH, Andersen OS. History and outcomes of fifty years of physician-scientist training in medical scientist training programs. Academic medicine: journal of the Association of American Medical Colleges. 2017;92(10):1390.

15. Weaver AN, McCaw TR, Fifolt M, Hites L, Lorenz RG. Impact of elective versus required medical school research experiences on career outcomes. Journal of Investigative Medicine. 2017;65(5):942-8.

16. Hall AK, Mills SL, Lund PK. Clinician-investigator training and the need to pilot new approaches to recruiting and retaining this workforce. Academic Medicine. 2017;92(10):1382.

17. Goldhamer MEJ, Cohen AP, Bates DW, Cook EF, Davis RB, Singer DE, et al. Protecting an endangered species: training physicians to conduct clinical research. Academic Medicine. 2009;84(4):439-45.

18. Green EP, Borkan JM, Pross SH, Adler SR, Nothnagle M, Parsonnet J, et al. Encouraging scholarship: medical school programs to promote student inquiry beyond the traditional medical curriculum. Academic Medicine. 2010;85(3):409-18.

19. Ommering BW, van den Elsen PJ, van der Zee J, Jost CR, Dekker FW. Using an extracurricular honors program to engage future physicians into scientific research in early stages of medical training. Medical science educator. 2018;28(2):451-5.

20. Laskowitz DT, Drucker RP, Parsonnet J, Cross PC, Gesundheit N. Engaging students in dedicated research and scholarship during medical school: the long-term experiences at Duke and Stanford. Academic Medicine. 2010;85(3):419-28.

21. Wolfson RK, Alberson K, McGinty M, Schwanz K, Dickins K, Arora VM. The impact of a scholarly concentration program on student interest in career-long research: a longitudinal study. Academic Medicine. 2017;92(8):1196-203.

22. Kaufman DM, Mann KV. Teaching and I earning in m edical e ducation: $h$ ow t heory c an i nform p ractice. Understanding Medical Education.16.

23. Vereijken MWC, Van Der Rijst RM, Van Driel JH, Dekker FW. Authentic research practices throughout the curriculum in undergraduate medical education: Student beliefs and perceptions. Innovations in Education and Teaching International. 2020;57(5):532-42.

24. Ryan RM, Deci EL. Self-determination theory and the facilitation of intrinsic motivation, social development, and well-being. American psychologist. 2000;55(1):68.

Page 9/11 
25. Swanwick T. Understanding medical education. Understanding Medical Education: Evidence, Theory, and Practice. 2018:1-6.

26. Kern DE. Overview. In: Thomas PA, Kern DE, Hughes MT, Chen BY, editors. Curriculum Development A Six-Step Approach for Medical Education. 3. Baltimore, Maryland, US: Johns Hopkins University Press; 2016.

27. Laidlaw A, Guild S, Struthers J. Graduate attributes in the disciplines of Medicine, Dentistry and Veterinary Medicine: a survey of expert opinions. BMC Med Educ. 2009;9:28.

28. Barrows HS. A taxonomy of problem-based learning methods. Medical education. 1986;20(6):481-6.

29. Laidlaw A, Aiton J, Struthers J, Guild S. Developing research skills in medical students: AMEE Guide No. 69. Med Teach. 2012;34(9):e754-71.

30. Bandura A. Social foundations of thought and action. Englewood Cliffs, NJ. 1986;1986(23-28).

31. Bertram D. Likert Scales are the meaning of life: academia.edu; [Available from: https://www.academia.edu/8160815/Likert_Scales_are_the_meaning_of_life.

32. Liu C, Scott KM, Lim RL, Taylor S, Calvo RA. EQClinic: a platform for learning communication skills in clinical consultations. Med Educ Online. 2016;21:31801.

33. Lewis JR. IBM computer usability satisfaction questionnaires: Psychometric evaluation and instructions for use. International Journal of HumanComputer Interaction. 1995;7(1):57-78.

34. Herrmann J. Evaluation von E-Learning. In: Giessen Uo, editor. Giessen, Germany: Koordinationsstelle Multimedia (KOMM) am HRZ der JLU Gießen; 2009.

35. Wagenmakers E-J, Ly A, Boutin B, Meerhoff F, Goosen J, de Jong T, et al. JASP. 0.14.1 ed. Amsterdam Netherlands: University of Amsterdam, Department of Psychological Methods.

36. Halter C. Quantitative Analysis with JASP open-source software2020.

37. Goh P-S, Sandars J. A vision of the use of technology in medical education after the COVID-19 pandemic. MedEdPublish. 2020;9.

38. van der Keylen P, Lippert N, Kunisch R, Kühlein T, Roos M. Asynchronous, digital teaching in times of COVID-19: a teaching example from general practice. GMS J Med Educ. 2020;37(7):Doc98.

39. Woodruff AE, Jensen M, Loeffler W, Avery L. Advanced screencasting with embedded assessments in pathophysiology and therapeutics course modules. Am J Pharm Educ. 2014;78(6):128.

40. Bennett C. How long should an e-learning course be? eLearn. 2007;2007(8):2.

41. Chatterjee D, Corral J. How to Write Well-Defined Learning Objectives. J Educ Perioper Med. 2017;19(4):E610.

42. Wass V, Van der Vleuten C, Shatzer J, Jones R. Assessment of clinical competence. The lancet. 2001;357(9260):945-9.

43. Bandura A. Self-Efficacy: The Exercise of Control, WH Freeman and Company, New York, NY. 1997.

44. Siemens G. Connectivism: A Learning Theory for the Digital Age http://www. elearnspace. org. Articles/connectivism htm (Accessed: 01/03/2007). 2005.

45. Goldie JGS. Connectivism: A knowledge learning theory for the digital age? Medical teacher. 2016;38(10):1064-9.

\section{Figures}



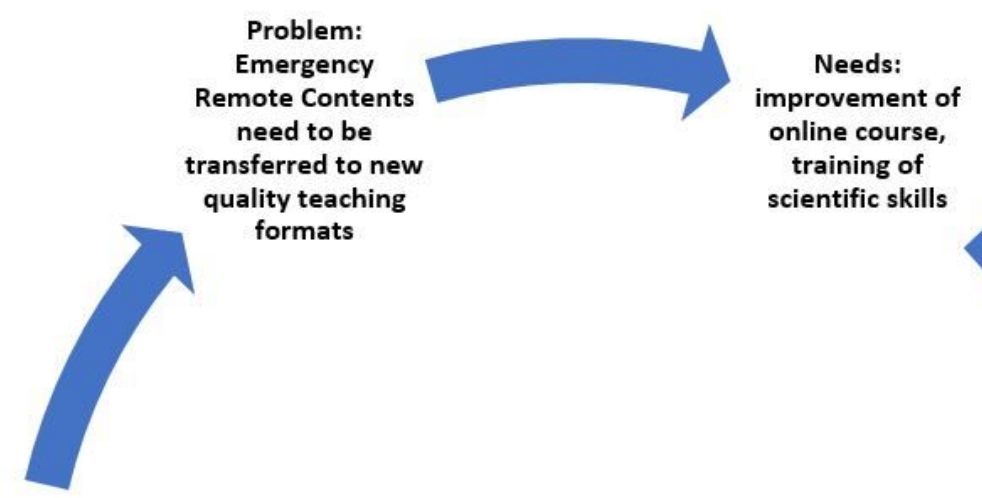

Evaluation

Classic semester evaluation

In-depth evaluation of newly designed course

using questions adapted from the literature

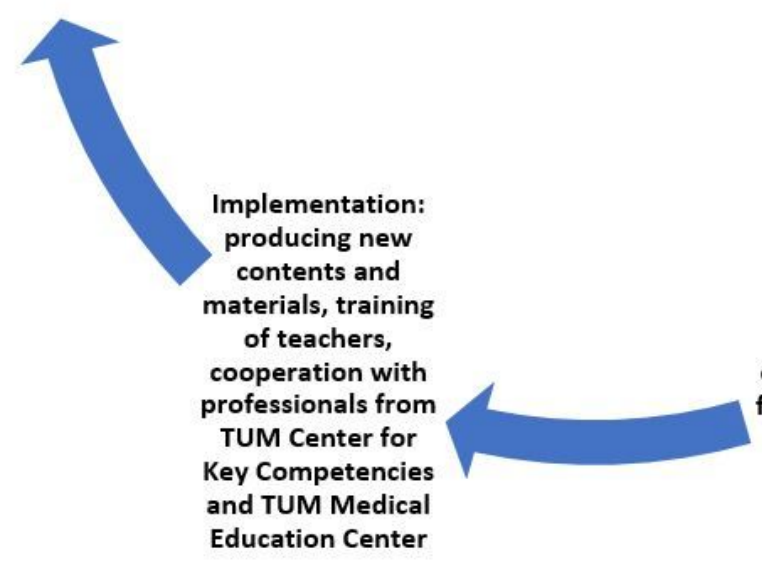

Goals / objectives: Flipped Classroom concept, project phase including training of scientific skills, improvement of materials

Educational

strategies, self-

directed learning,

flipped classroom,

connectivism

Figure 1

Development process in transition phase, adapted from Kern et al. (26)

\section{Supplementary Files}

This is a list of supplementary files associated with this preprint. Click to download.

- AllPathOnsupplement.docx 